\title{
Manually Produce Clay-Based Housing Materials in Rural Area
}

\author{
Baixin $\mathrm{Wu}^{1}$, Haifeng $\operatorname{Yan}^{1} \&$ Ao Sun ${ }^{1}$ \\ ${ }^{1}$ Hunan Institute of Animal Husbandry and Veterinary Medicine, Changsha, China \\ Correspondence: Baixin Wu, Hunan Institute of Animal Husbandry and Veterinary Medicine, CN410131, \\ 8\#Changlan Route (Quantang), Furong District, Changsha City, China. Tel: 86-138-7489-3158. E-mail: \\ wbx503@163.com
}

Received: November 1, 2016

Accepted: November 24, 2016

Online Published: January 15, 2017

doi:10.5539/jas.v9n2p104

URL: http://dx.doi.org/10.5539/jas.v9n2p104

\begin{abstract}
Rural housing materials in developing countries (such as African countries) are mostly (crop) straw for roof cover, soil and tree branch for (round) wall. The houses are small with interior dark. In the case of electricity, mechanical and economic conditions are not allowed, farmers hardly know how to improve housing conditions or create economic benefits by applying manual labour, animal power, land, timber and fuel (firewood or coal). In this article, the method of manually producing baked tiles (for roof cover) and bricks (for wall) are described in detail with a set of historic pictures, which aims to inherit Chinese farmers' wisdom and diligence (intangible cultural heritage), arouse farmers in developing countries to improve their housing conditions by self reliance, promote the rise and development of rural industry, at the same time, promote the construction of water conservancy project.
\end{abstract}

Keywords: mud, mould, tile, brick, kiln, burn

\section{Introduction}

Rural housing materials mainly contain wall and roof cover materials. The primary function is to withstand wind, rain or snow into the building (Guofeng, 2005; Tiansheng \& Hong, 2010). Modern wall materials largely consist of baked bricks and mechanical moulding hollow clay bricks or concrete bricks among which the baked bricks account for $70 \%$ of wall materials (Xiaoguang, 1991). Modern roof cover materials mostly refer to baked tiles or glazed tiles. The process flow for the production of these materials mainly consists of earth cutting (with bulldozer), transferring (carry scraper), adding water (running water, hot water or steam), mixing (blender), filtrating, squeezing out (extrusion machine and conveyor belt), cutting unbaked tiles or bricks (cutting machine, plastic compression molding machine), glazing (for glazed tiles), drying, transferring into a tunnel kiln (tractor or conveyor belt) and firing (Situ, 1991; Chengcai, 1994; Xiaoxi, 2000; Zuxian, 2012). In a word, modern production method of the materials needs machine, fuel (diesel oil), electricity, etc. Farmers in developed countries have the economic ability to buy these materials. Most of them have brick \& tile structured housing that is spacious and bright.

Many farmers' houses in rural area in developing countries (such as African countries) looked like haystacks. Some dry tree branches or wooden sticks were inserted into ground to form a circular enclosure and become a wall after mud put in around it. Crop straw (or cattle dung, houses of a few nomadic farmers) was covered on a conical (or planiform) framed roof. The houses were small with interior dark, the wall and roof difficult to resist extreme weather such as rainstorm or high temperature (Baixin, 2016). There was no one who did not want to change his own house into spacious and bright. However, most of them could not be affordable to buy, some even had never seen, modern construction materials.

Before 1960s, there were also many houses constructed with naturally dry clay bricks for wall and crop (rice or wheat) straw for roof in rural area in China. The level of rural economy was very low. From then on, farmers forged ahead and manually produced baked tiles and bricks by self-reliance. The housing situation gradually changed. However, the traditional workshop of manually producing clay-based baked tiles and bricks gradually disappeared with the rapid development of economy. In this article, the method of manually producing baked tiles (for roof cover) and bricks (for wall) are described in detail with a set of historic pictures, which aims to inherit Chinese farmers' wisdom and diligence (intangible cultural heritage), arouse farmers in developing 
countries to improve their housing conditions by self reliance, promote the rise and development of rural industry, at the same time, promote the construction of water conservancy project.

\section{Method of Manually Producing Baked Tiles and Bricks}

\subsection{Preparation of Mud}

The main material for making baked tiles or bricks is clay. The silt, shale, coal gangue and flyash (mixed with clay) can also be used. The intensity of burnt clay is stronger than dry clay due to the content of silicon dioxide and aluminium oxide (Table 1, Linwei, 2005). Temporary work shed should be initially built near clay digging place. Removing the topsoil, digging and sprinkling water to make the soil soaked for 2 days. The soaked soil is repeatedly trampled by human feet when its quantity is small or by a cattle (Figure 1) when large. When the soil becomes dough-like mud (Figure 2) it is transferred into the work shed. The mud should be stacked into a number of cuboid shapes (height $28-30 \mathrm{~cm}$ and length $82-85 \mathrm{~cm}$ ) when used for unbaked tile or any shapes when used for unbaked brick. Water should be sprinkled over the mud in the shed to keep certain moisture so as to be easily handled.

Table 1. Main ingredients of clay

\begin{tabular}{lll}
\hline Chemical composition & Content $(\%)$ & Main effect \\
\hline Silicon dioxide & $55-70$ & Strength of products \\
Aluminium oxide & $15-20$ & Strength of products \\
Iron sesquioxide & $4-10$ & Colorant \\
Calcium oxide & $0-10$ & Fluxing agent \\
Magnesium oxide & $0-3$ & Fluxing agent \\
Sodium oxide/ Burnt potash & a little & Fluxing agent \\
Organics & $3-15$ & Bad material fall off \\
\hline
\end{tabular}

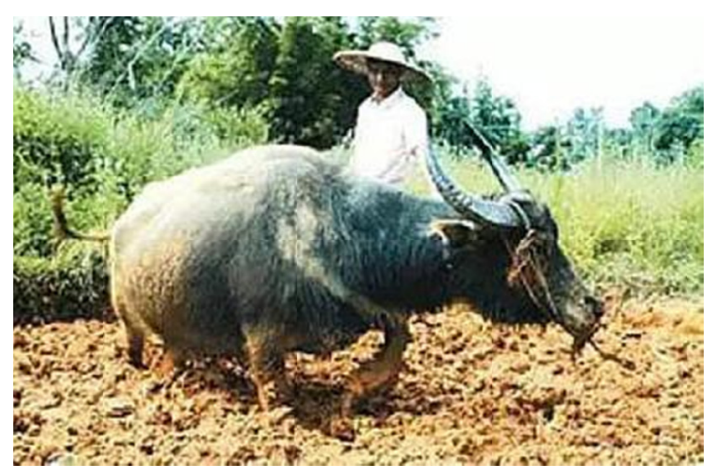

Figure 1. A Chinese farmer was guiding the cattle to trample over the soaked soil

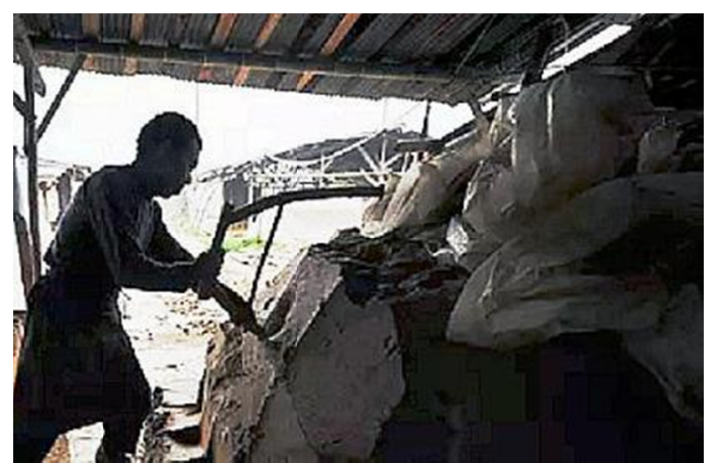

Figure 2. The mud transferred to the shed was ready for unbaked tiles or bricks 


\subsection{Production of Baked Tiles}

\subsubsection{Preparation of Tile Mould and Unbaked Tiles}

Tile mould, $26-30 \mathrm{~cm}$ width and 80-82 $\mathrm{cm}$ length, is made of planks $(1-1.5 \mathrm{~cm}$ width and $26-30 \mathrm{~cm}$ length) connected by 2 wires. It looks like a hollow cylinder when rolled up (Figure 3). There are 4 raised battens outside the cylinder, which is upright and uniformly spaced. The (future) mud enwrapped here will be relatively thin so that it can be easily divided into 4 pieces when dry (Liyi, 2016). The sheath of tile mould seems to a bag without bottom. A piece of gauze (cloth) is fixed around a round wire (or bamboo) rack. The sheath is used to cover the tile mould and will be covered by mud so that the mould and sheath can be easily removed from the mud.

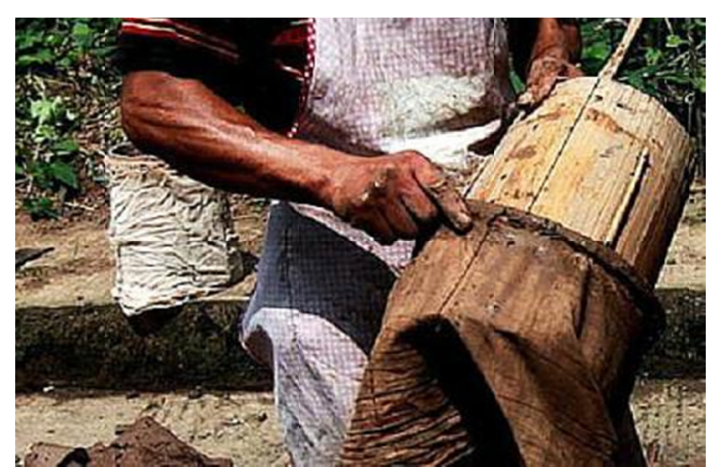

Figure 3. Tile mould was being covered by its sheath

A piece of mud (length $82-85 \mathrm{~cm}$, width $26-30 \mathrm{~cm}$ and thickness $1 \mathrm{~cm}$ ) is cut by the bow, which is made of an iron wire and a bent tree branch (Figure 4). The mud enwrapped the sheath and mould (Figure 5 left) is sprinkled with water and made smooth by a scraper (Figure 5 right). The top spare mud ( $25 \mathrm{~cm}$ away from the bottom) is cut and removed by a nail in the rectilinear scale, which is $25 \mathrm{~cm}$ away from the long end (Figure 6 left). The mould rolled up towards inside from the interface position so as to be easily removed. The sheath is then carefully taken out and a cylinder shape mud ready (Figure 6 right). Another one is made according to the same steps (Figure 7). Each dry cylinder shape mud is carefully broken apart into 4 unbaked tiles and erectly stacked (Figure 8).

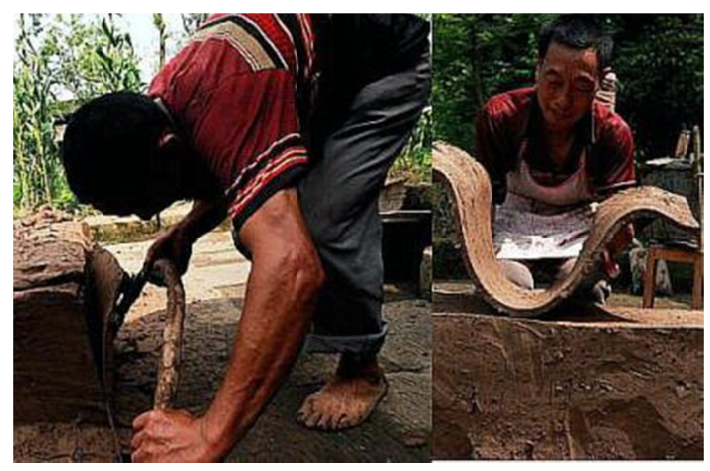

Figure 4. A piece of mud was cut by the bow wire 


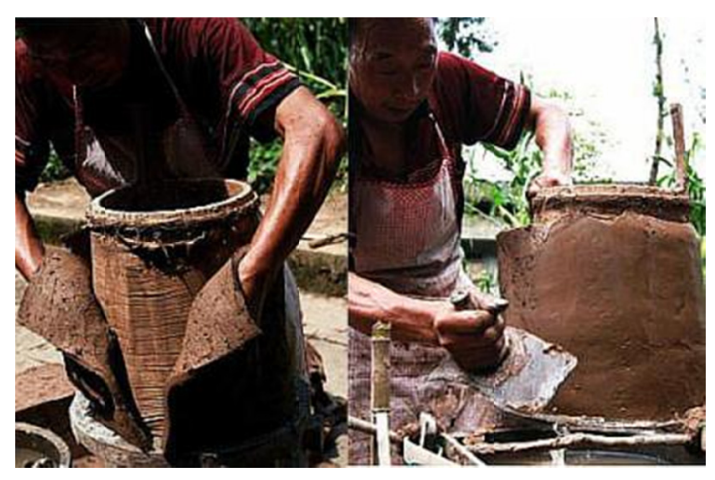

Figure 5. The mud enwrapped the sheath and mould (left) was sprinkled with water and made smooth by a scraper (right)

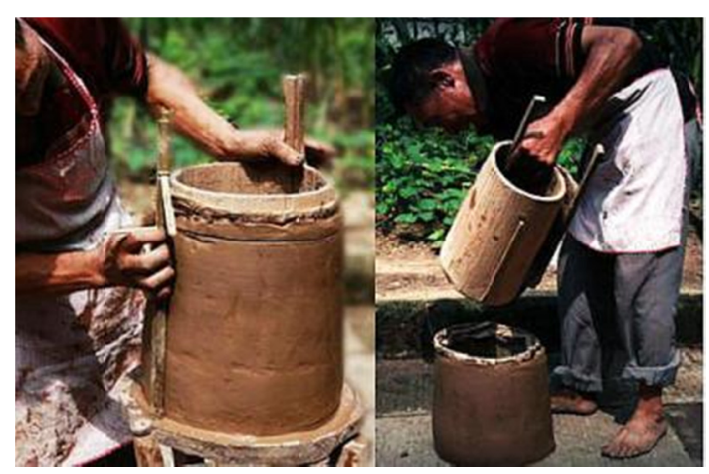

Figure 6 . The top spare mud was cut by a nail in the rectilinear scale (left) and the mould taken out (right)

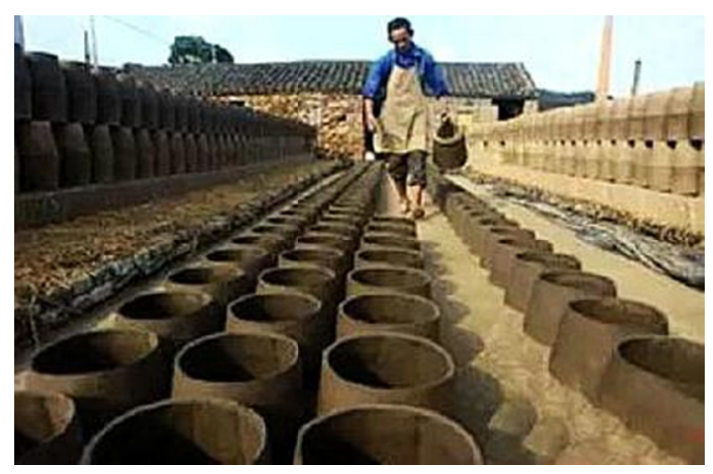

Figure 7. The man would put down another cylinder shape mud on the ground 


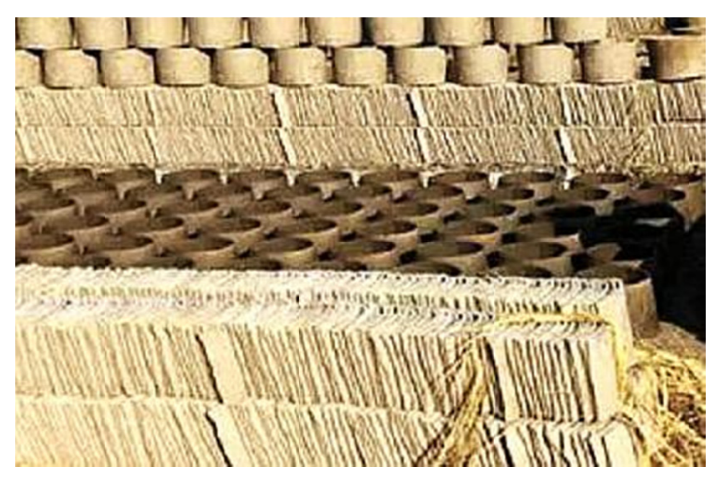

Figure 8. Each dry cylinder shape mud was broken apart into 4 unbaked tiles and erectly stacked

\subsubsection{Transferring the Dry Unbaked Tiles into a Kiln and Firing}

The dry unbaked tiles are transferred into a kiln (Figure 9), which should be previously prepared, and laid up row by row from the wall (Figure 10). The spacing between every two rows is $8-10 \mathrm{~cm}$ for fire passageway. The shape of kiln looks like a cylinder or cellar (Figure 11). There is an outlet flue on the top and one door opening in the bottom for people (unbaked tiles or firewood) getting in and people (baked tiles or ash) out.

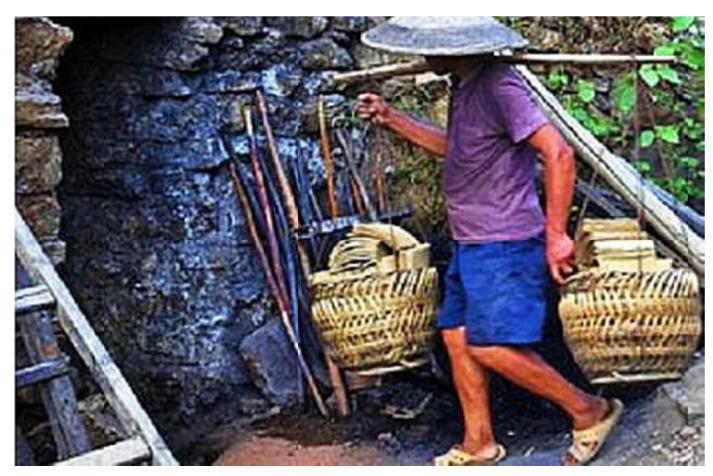

Figure 9. The man was transferring dry unbaked tiles into the kiln

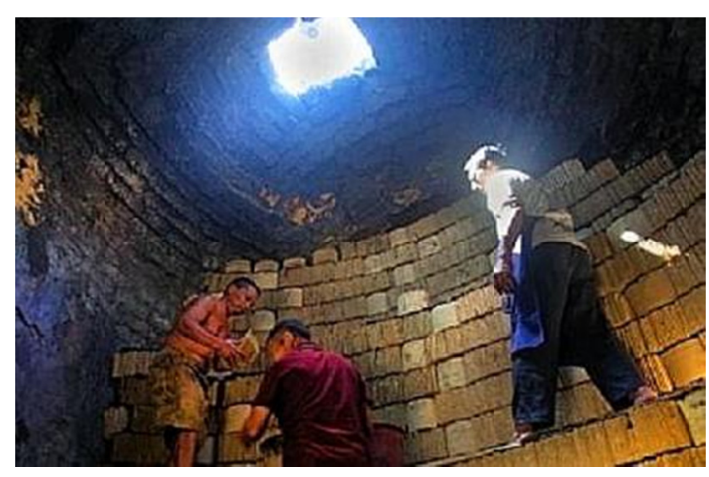

Figure 10. The workers were laying up dry unbaked tiles in the kiln 


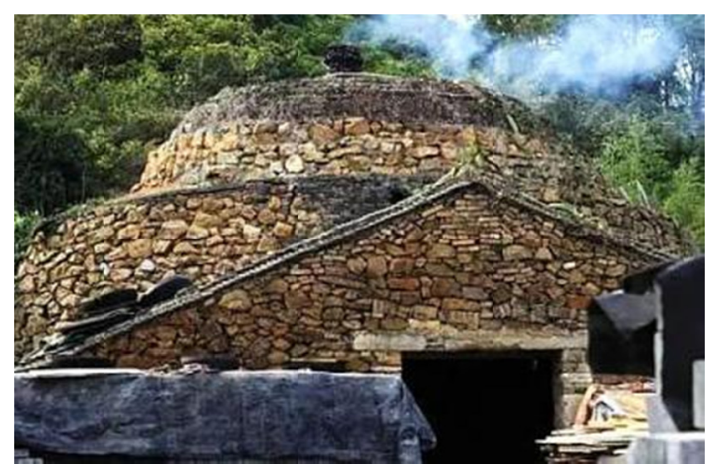

Figure 11. Dry unbaked tiles were being burnt in the kiln

When the unbaked tiles are ready in the kiln, firewood is piled up inside the door opening and burnt. An iron plank closing the door openings is removed a little or more to control fire power. In the initial 9-10 days (first stage), weak fire should be applied to evaporate slowly the moisture in the unbaked tiles. Otherwise the baked tiles will have cracks. $4-8 \%$ of artificially added water in the clay gradually evaporates when the temperature is 40-200 ${ }^{\circ} \mathrm{C}$ (Huaixiang, 1957). In the next 6-7 days (second stage), strong fire is used. The door opening in the bottom should be closed to enlarge the drawing strength of outlet flue. The unbaked tiles will not be well burnt when the fire power is insufficient or deformed when it is excessive. The chemically combined water in the clay $\left(\mathrm{Al}_{2} \mathrm{O}_{3} \cdot 2 \mathrm{SiO}_{2} \cdot 2 \mathrm{H}_{2} \mathrm{O}\right)$ changes into dehydrated clay $\left(\mathrm{Al}_{2} \mathrm{O}_{3} \cdot 2 \mathrm{SiO}_{2}\right)$ and water $\left(2 \mathrm{H}_{2} \mathrm{O}\right)$ when the temperature reaches to $500-600{ }^{\circ} \mathrm{C}$ (Huaixiang, 1957). Lastly (third stage) the fire is stopped. When the temperature reaches to $850-900{ }^{\circ} \mathrm{C}$, the dehydrated clay $\left(\mathrm{Al}_{2} \mathrm{O}_{3} \cdot 2 \mathrm{SiO}_{2}\right)$ becomes the mixture of Aluminium oxide $\left(\mathrm{Al}_{2} \mathrm{O}_{3}\right)$ and Silicon dioxide $\left(2 \mathrm{SiO}_{2}\right)$, which is called baked tile (Huaixiang, 1957). It is observed from the outlet flue on top or the door opening in the bottom when the whole height of unbaked tiles descends 4-5 cm or inclines 7-8 $\mathrm{cm}$ or the tiles' color has changed into grey (Figure 12), the fire should be stopped. Then about 15 days later, baked tiles can be transferred out and used (sold) for construction (roof cover) material.

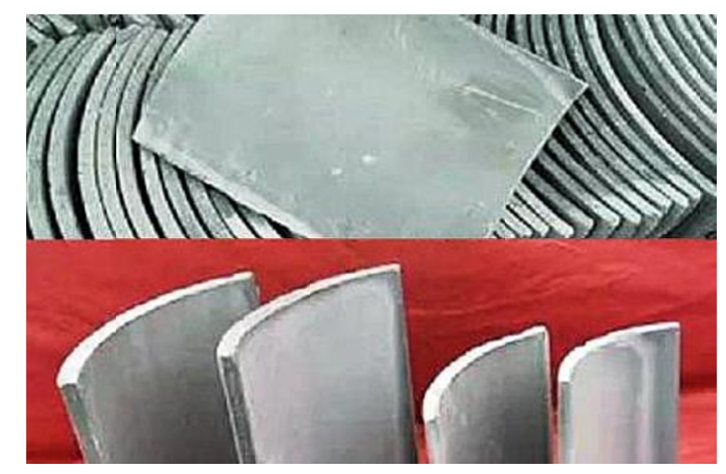

Figure 12. Baked (grey) tiles

\subsubsection{Usage of Baked Tiles}

The size of a baked tile is generally $25 \mathrm{~cm}$ length by $20 \mathrm{~cm}$ width) by $1 \mathrm{~cm}$ thickness (Jijin, 2015). The support on roof consists of a few wood stretched over two walls and planks fixed on the wood. The width of a plank is about $8 \mathrm{~cm}$. The interval between two planks is approximately $12 \mathrm{~cm}$. Each two intervals among 3 planks are covered with two tiles which are concave upward and both ends contact $4 \mathrm{~cm}$ of the plank. Every two ends of the tiles on a plank are covered by another tile which is concave downward. The entire roof is covered with tiles according to the same procedures. The function of concave upward tiles is mainly receiving rainy water and making it fall down to ground whereas concave downward tiles are preventing water from dropping into house. Baked bricks should be constructed on the top or both top and bottom of inclined plane so as to fasten the tiles (Figure 13). If leaking inside the house after a much heavy rain, the area of roof should be checked or replaced by new tiles (Figure 14). 


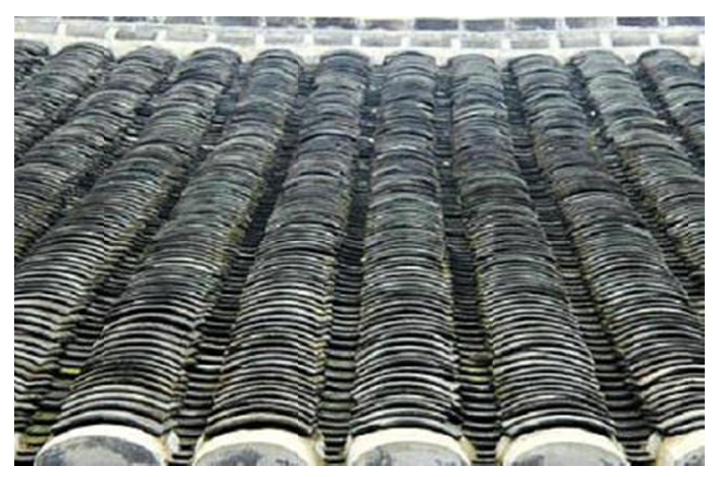

Figure 13. A part of roof covered by baked tiles

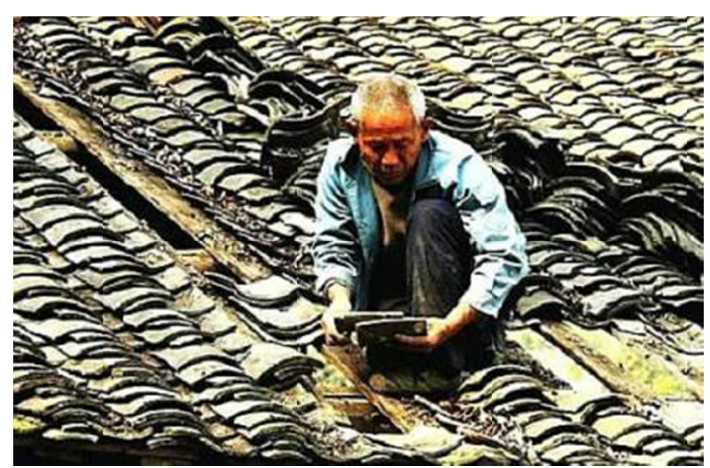

Figure 14. The aleak site of tiles roof after years was being checked and covered again

\subsection{Production of Baked Bricks}

\subsubsection{Preparation of Brick Mould and Unbaked Brick}

Brick mould (Figure 15 right), $24.5 \mathrm{~cm}$ length, $12 \mathrm{~cm}$ width and $5.8 \mathrm{~cm}$ height, is made of two long planks (35 $\mathrm{cm}$ length and $5.8 \mathrm{~cm}$ width) and two short planks $(12 \mathrm{~cm}$ length and $5.8 \mathrm{~cm}$ width), which the short ones are inserted in the long ones. The two ends of the long are used as handle. The mould, previously soaked in water for a few seconds, sprinkled a little sand on the inside wall and put on a table or ground after taking out, is filled up with mud, compressed, removed erectly and an unbaked brick ready.

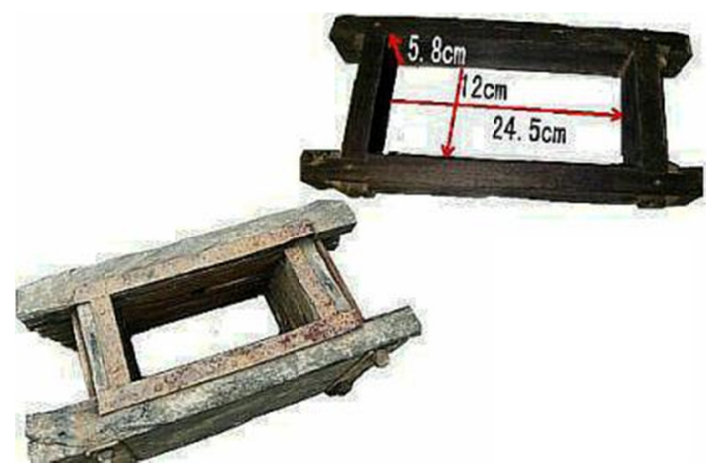

Figure 15. One brick mould (right) and four pieces of mould fixed by active button (left)

Four pieces of brick mould can be temporarily fixed together by active button (Figure 15 left), filled up with mud and transferred to outside. The active button is loosened. The gap between two pieces of mould is cut by the bow wire, three pieces of brick mould removed, the first mould taken out, then the second (third and fourth) 
mould taken out according to the same steps. Hence, 4 pieces of unbaked bricks can be made at the same time (Figure 16).

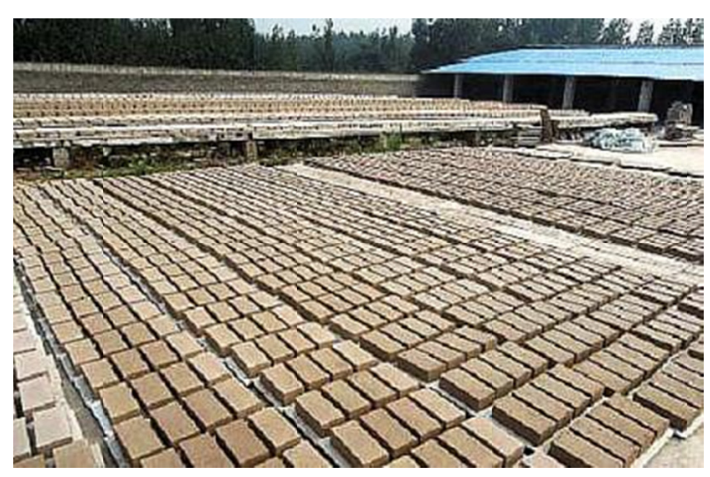

Figure 16. Many unbaked bricks were staying outside the work shed to become dry

\subsubsection{Transferring the Dry Unbaked Bricks into a Kiln and Firing}

The kiln (previously prepared) used for burning unbaked bricks in rural area commonly includes small type of kiln which has only one door opening and one outlet flue (Figure 17) and corridor shaped kiln (Figure 18). There are a high chimney for exhaust emission and a few holes for adding fuel (coal) on the top and some door openings in the bottom for people (unbaked bricks in a handcart) getting in and out. The dry unbaked bricks are transferred into the kiln and laid up by one row lying and other row standing. The spacing between every two standing bricks is $5 \mathrm{~cm}$ for fire passageway. The initial fuel (nubbly coal) is placed between every 4 or 5 rows of brick.

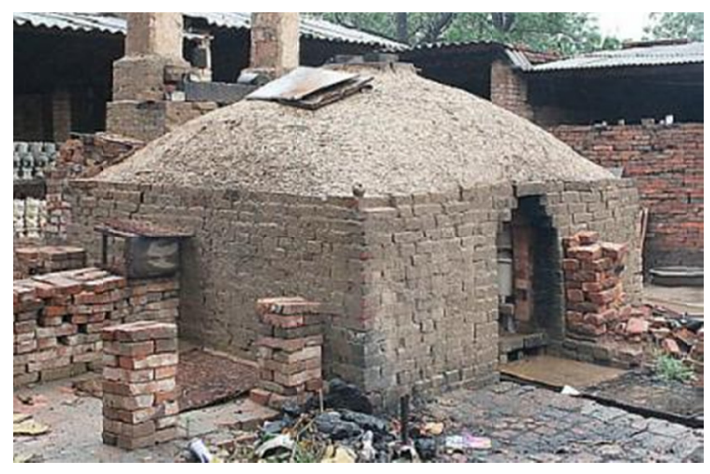

Figure 17. A kind of small kiln used for unbaked bricks

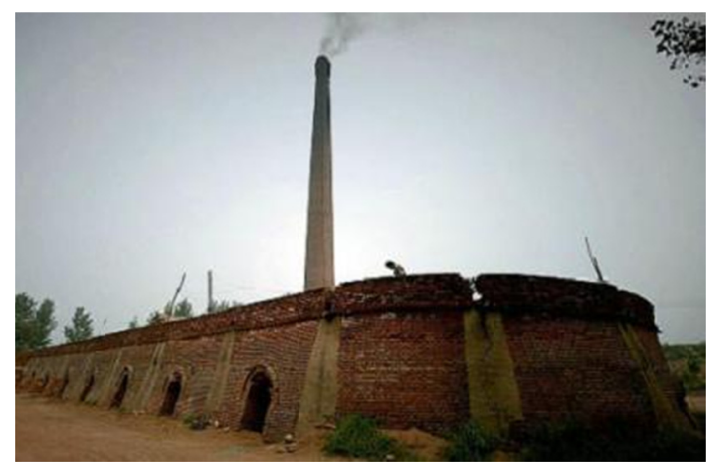

Figure 18. Dry unbaked bricks were being burnt in the corridor shaped kiln 
When unbaked bricks and (inside) fuel are ready in the kiln, firewood is piled up in the door openings and burnt. Iron planks closing the door openings are removed a little or more to control fire power. Some (outside) fuel (coal) is added through holes on top during burning period when needed. In the initial 9-10 days (first stage), weak fire should be applied to evaporate slowly the moisture in the unbaked bricks. Otherwise the baked bricks will have cracks. In the next 6-7 days (second stage), strong fire is used. All the door openings in the bottom should be closed to enlarge the drawing strength of chimney. The unbaked bricks will not be well burnt when the fire power is insufficient or deformed when it is excessive. Lastly (third stage) the fire is stopped. It is observed from the top holes or the door openings in the bottom when the whole height of unbaked bricks descends or inclines or the bricks' color become red (Figure 19), the fire should be stopped and all of door openings should be opened to let the hot bricks become cool easily. Then about 15 days later, baked bricks can be transferred out and used (sold) for (wall) construction material.

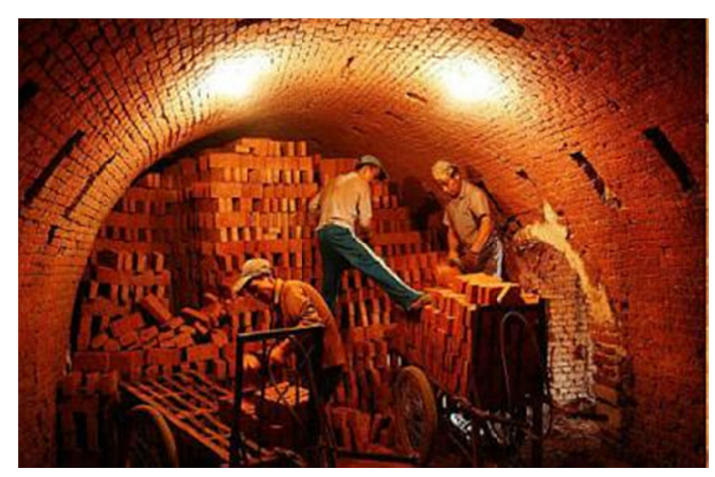

Figure 19. Baked (red) bricks were being transferred out by the farmers

\subsubsection{Usage of Baked Bricks}

The standard size of a baked brick is $24 \mathrm{~cm}$ by $11.5 \mathrm{~cm}$ by $5.3 \mathrm{~cm}$. The error should be within $0.3 \mathrm{~cm}$ (Linwei, 2005). The thickness of mortar joint is $1 \mathrm{~cm}$. About 128 bricks needed for the construction of per square meter (512 bricks for each cubic meter) of wall ( $24 \mathrm{~cm}$ of thickness). The bricks can be constructed as horizontal type or vertical type. In general, a bearing wall is constructed with horizontal bricks whereas a partition wall with vertical bricks (Figure 20).

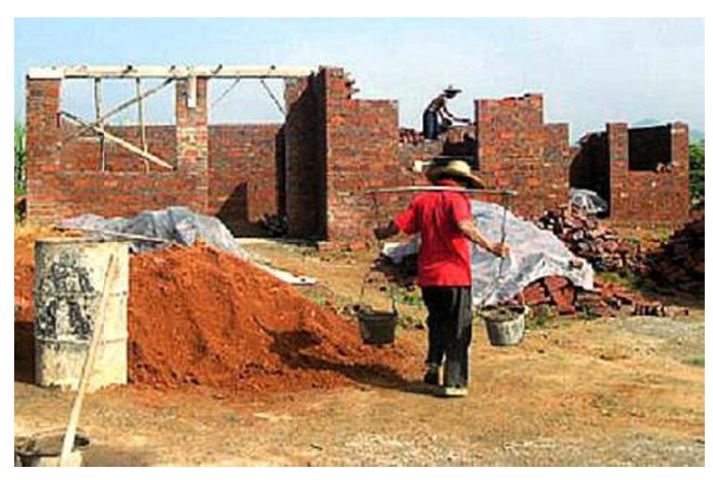

Figure 20. A kind of house was being constructed with baked bricks

\section{Discussion}

It is time-saving, labor saving, size consistent and standardized, high efficient to produce commercial clay-based tiles or bricks with modern equipment. But the investment cost is large and the price of products is higher. It is time consuming, arduous, accurate size uncertain and low efficient to produce the materials manually. However, the equipment needed is simple, the investment cost less and the price of products lower if for commercial purpose (Nana, 2010). Developing countries have resources of land, forest, mineral (coal, iron, etc.), human 
power and livestock power, etc. Under the premise of unavailable mechanical equipment, fuel (diesel) electricity, etc. and the condition of low economic level, manually producing clay-based tiles and bricks has applicability and feasibility. Firstly, small types of tile kiln and brick kiln are recommended to be promoted. A small amount of tiles and bricks produced for the purpose of improving the producers' own houses. Secondly, large types are tried to be built and a lot of materials produced for commercial purpose so as to improve other farmers' houses. Lastly, the great improvement of rural and urban housing construction will be realized by transition to modern production.

It is affected by climate when producing clay-based materials manually, because earth cutting and drying of unbaked tiles or bricks are handled outdoor. The optimum conditions for the production are that the temperature $\geq 5{ }^{\circ} \mathrm{C}, 2-4$ level of wind and $60-80 \%$ of relative humidity, which mass production can be performed. It should be stopped when the lowest temperature $\leq-2{ }^{\circ} \mathrm{C}$ as the unbaked tiles or bricks will be cracked with cold. The windward side and top of stacked tiles or bricks outdoor should be covered with something when rainfall $\geq 0.5$ $\mathrm{mm}$. When it $\geq 5 \mathrm{~mm}$ drainage ditch should be dug. When the highest temperature $\geq 30{ }^{\circ} \mathrm{C}$, relative humidity $\leq$ $30 \%$ and wind level $\geq 6$, the unbaked tiles or bricks should be dried in the morning and evening so as to avoid direct exposure in strong sunshine. When more than 5 consecutive days of low cloud amount are $\geq 8$, the drying time should be prolonged (Jinping, 2012).

Yearly total brick production in China was 600 billion, which consumed 1.3 billion $\mathrm{m}^{3}$ of clay resource, equivalent to 46667 hectares of land destroyed each year that calculated according to $3 \mathrm{~m}$ of average depth of excavation (Nana, 2010). Hence, the destruction of arable land should be avoided when producing the materials manually. The production would emit harmful gases and waste water (Haiying, 1994). Therefore, the kiln should be built far away from residential area, animal farm and crop production area.

The development of agricultural production can not be separated from irrigation. There are many rivers and lakes in developing countries that can be used for irrigation. But the land that is far away from a river or lake needs irrigation canal built to get irrigation. Under the condition of limited national financial resources, construction of irrigation channel is very difficult. If guiding and administrating the construction material producers to cut earth from rivers (lakes) nearby to the area where irrigation is needed, construction of irrigation channel would be probably achieved. Assuming the earth cutting is $3 \mathrm{~m}$ in width and $3 \mathrm{~m}$ in depth, 0.144 billion meters [= $1.3 /(3 \times 3)]$ or 144 thousands kilometers length of canal would be finished after 600 billion bricks produced.

\section{References}

Baixin, W. (2016). Better living facilities for African farmers. African Journal of Science and Research, 5(4), 48-49. Retrieved from http://ajsr.rstpublishers.com

Chengcai, Y. (1994). Producing tiles with clay in which has fly ash. Bricks and Tiles. Retrieved from http://www.brick-tile.com

Guofeng, S. (2005). Study on rainproof performance of roofing tiles. Bricks and Tiles. Retrieved from http://www.brick-tile.com

Haiying, W. (1994). Red brick production in Taiwan tends to shrink. Information of Building Materials Industry, 3(14). Retrieved from http://www.cnki.net

Huaixiang, L. (1957). Discussion on the basic theory of clay tiles during the course of baking. Building Materials Industry. Retrieved from http://www.cnki.net

Jijin, D. (2015). Disappearing traditional process of producing unbaked tiles. Retrieved from http://www.360doc.com

Jinping, L. (2012). The meteorological conditions and suggestions for red brick production. Animal Husbandry and Feed Science. Retrieved from http://www.cnki.net

Linwei, Z. (2005). The traditional firing craft of red brick kiln in Southern Fujian. The Chinese Journal for the history of Science and Technology, 26(3), 249-256. Retrieved from http://www.doc88.com

Liyi, H. (2016). Tiler-Let the clay reborn in the water and fire. Retrieved from http://news.beiww.com

Nana, X. (2010). Study on the destruction of solid clay brick production to land resources and the countermeasures. Journal of Henan University of Urban Construction, 19(3). Retrieved from http://www.cnki.net

Situ. (1991). Strictly control the quality of red bricks production. Construction Workers, 2(24). Retrieved from http://www.cnki.net 
Tiansheng, C., \& Hong, C. (2010). Analyzing the reasons for the slow development of China ancient building masonry structure. Jiangsu Construction, 47-49. Retrieved from http://www.cnki.net

Xiaoguang. (1991). Expectation of red bricks production in Beijing. China Building Materials, $1,35-36$. Retrieved from http://www.cnki.net

Xiaoxi, Z. (2000). Liquid static pressure forming and device for clay tiles. Hebei Ceramics, 28(3). Retrieved from http://www.cnki.net

Zuxian, C. (2012). Production process of color clay tiles. Bricks and Tiles. Retrieved from http://www.brick-tile.com

\section{Copyrights}

Copyright for this article is retained by the author(s), with first publication rights granted to the journal.

This is an open-access article distributed under the terms and conditions of the Creative Commons Attribution license (http://creativecommons.org/licenses/by/4.0/). 